\title{
DIAGRAMS OF EUROPEANIZATION: \\ EUROPEAN EDUCATION GOVERNANCE IN THE DIGITAL AGE
}

\author{
Mathias Decuypere \\ Laboratory for Education and Society, University of Leuven, Belgium \\ mathias.decuypere@kuleuven.be
}

\begin{abstract}
European education governance is increasingly affected by and effectuated through digital means. This article presents an analysis of the way in which Europe is increasingly deploying digital technologies, and more specifically websites, in order to shape and communicate its education policies. Drawing on the notion of the diagram as the multimodal combination of texts and visuals into a single plane, the article scrutinizes two websites that play a central role in the production and distribution of policy data: first, the European Commission's Directorate Education and Culture website presenting the Education and Training monitor; second, the Open Education Europa website stimulating the deployment of Open Education practices in Europe. Conceived as active devices, various diagrams on these websites are analyzed in view of the operations they perform. It is argued that these diagrams portray related interplays of absence and presence, enact specific spaces into being, and call for specific ways of taking action upon the reality they purport to represent. As such, diagrams have become an integral part of European education governance in the digital age.
\end{abstract}

\section{TO CITE THIS ARTICLE:}

Mathias Decuypere (2016) Diagrams of Europeanization: European education governance in the digital age, Journal of Education Policy, 31:6, 851-872, DOI:10.1080/02680939.2016.1212099

\section{AVAILABle at:}

http://dx.doi.org/10.1080/02680939.2016.1212099 


\section{Introduction}

Education governance is increasingly affected by and effectuated through digital means. Over the last years, the possibilities and opportunities of digital devices of all sorts have gained much attention from various policy-makers and organizations, and this both nationally as well as internationally. This paper focuses on recent developments at the European level in view of the role and functions of digital devices - especially websites - in European education governance. Indeed, given the many affordances of digital devices such as list servers, websites, publically available databases and so on, Europe's interest in the use and adoption of these tools is hardly surprising. The role of websites in the composition of European education governance is a complex, multi-layered, matter. Generally, it could be stated that Europe has embraced websites as tools that enable as much to distribute a sound educational knowledge base to interested stakeholders and experts as they assist in popularizing specific policy measures taken by its various Directorates to a broader interested public.

First, websites have greatly facilitated the capacity of transnational organizations to distribute the data they produce on a (potentially) global scale - i.e. to every person with an internet connection. The process of data production is a notoriously intricate matter in which research and policy actors are complexly intertwined, databases such as PISA and PIAAC co-constructed by a variety of actors and organizations, and so on (Grek 2010). Accordingly, the eventual presentation of these data on websites might be perceived as the - provisional - end-stage of an ever-more concentrated and constantly looping cascade of (general) databases, (specific) numbers, (propagated) policy directions, (advocated) measures, etc. which are eventually stabilized as 'information' (visually and/or textually) on a digital page. As evident as this process of assembling both social (policy actors, ministers, European commissioners, think tanks, ...) and material (databases, servers, ...) actors into one singular website might sound in our present constellation of oversaturated digital presence, this article argues that data distribution does not so much entail a merely innocuous (objective) digital representation of measures undertaken, but rather enacts significant consequences with respect to contemporary education governance (Lawn 2011; Williamson 2015a).

These consequences have only recently started to receive interest from educational researchers. Some first analyses have dealt with the precise ways in which these data are disseminated and presented by and through online means. In this respect, design, lay-out, and overall setup of the digital media adopted play a crucial role, focusing on issues as: the precise composition of policy websites; the messages that digital data convey; the implicit assumptions, ideologies, and normativities present; etc. Additionally, a distinction is often made between more traditionally structured web pages consisting largely of textual information on the one hand, and information with which the user needs to actively interact on the other hand. As far as the latter is concerned, different interactive visualization tools have started to proliferate on websites, allowing and inviting the user to tweak different parameters which in turn generate different (visual) results (Edwards 2015; Selwyn 2015; Williamson 2015a). However, whether websites and webpages are largely composed out of text (and some complementary visuals) - reminiscent of the traditional book page - or precisely require further actions of the user, in both cases the concrete modalities by means of which information is distributed perform specific operations that have come to assist the governance of the educational (policy) field: some measures are prioritized over others, explicit points of action are propagated and/or discouraged, etc. In the process and through the operations of these devices, desired ways of organizing education or desired future courses of action are being stabilized and seeking to steer and reconfigure user actions (Fenwick and Edwards 2016; Rose 1999).

Second, and closely related hereto, websites are equally often invoked to popularize particular quantitative and/or qualitative - measures one wants to undertake. It is at this point that websites 
harbor unique capabilities that are difficult to fulfill by means of analog media (alone): in their interactive combining of written and visual elements, they regularly serve as a rhetorical device that not only conveys particular sorts of information, but that equally persuades by combining contents with esthetics, interactivity, ease of use, accessibility, and so on (Galloway 2012). As distinct sorts of interfaces, websites constitute a zone of (esthetic) activity that is greatly efficient in stressing particular aspects of the matter one presents (and others not); conveying particular sorts of information (and others not); implying particular actions to undertake (and others not); etc. As such, websites never merely communicate information, but are always active devices that aim to persuade, highlight, keep out of view, and so on. Especially in education policy contexts, where large data-sets are nowadays one of the focal matters on which various policies around the globe are being based, this popularizing feature of websites is increasingly being made use of and actively exploited in order to circulate ideas and convey information (Williamson 2015b). As such, choices regarding what is to be popularized, what is to be highlighted, and so on, configure the ways in which education policy spreads information to the general public, and hence, the ways in which this policy and data come into being for this public (Decuypere, Ceulemans, and Simons2014).

In the context of European education governance, this entwined, difficult to differentiate, dynamic of data dissemination and popularization has resulted in European websites being actively deployed to govern the educational field. Whereas literature tends to focus mostly on the way in which data have come to govern education (e.g. Ozga 2009; Selwyn, Henderson, and Chao 2015), in this article we argue that websites (and what is presented by them) equally play a significant role herein. In its most general terms, the interest in and adoption of digital devices has facilitated the composition and consequential governance of what could be called a European educational space. The fabrication of this space has already been subject of systematic scrutiny (e.g. Ball 2015; Lawn and Grek 2012), yet its specific digital fabrications have not yet received much attention. Naturally, these concrete manifestations differ in view of the content to be presented. For instance, on the one hand the European Commission's Directorate General Education and Culture (henceforth DG EAC) has a rich history of and involvement in generating numerical educational knowledge and policies based on this knowledge. Correspondingly, a variety of accounts has analyzed how DG EAC is increasingly making use of what has been termed as a governing by numbers and consequential comparison (Grek 2008; Nóvoa, Carvalho, and Yanes 2014). These quantitative data are not simply 'there,' but need to be distributed and popularized by digital means. The DG EAC's yearly Education and Training monitor, for instance, is a digital tool that distributes, in a very accessible manner, how well Europe's member states perform on a yearly basis. $\stackrel{1}{\text { At }}$ the same time that a European interest in numbers, benchmarks, and standards has proliferated, on the other hand, equally many forms of soft(er) governance have emerged that seek to provide very concrete examples of good practices (Hargreaves 2003; Lawn 2006; Simons 2014). Again, the affordances of digital instrumentalia play a crucial role herein, in the sense that their ability to provide a profusion of examples to a European public facilitates the attractive dispersion and demonstration of concrete practices that 'work.' The DG EAC's EPALE (ePlatform for Adult Learning in Europe) website is an instructive example in this respect, concretely demonstrating how websites are nowadays an inextricable part of the distribution and popularization of qualitative, soft evidence to an interested public. ${ }^{2}$ In sum, websites are greatly assistive in composing a European educational policy space, distributing and popularizing both hard as well as soft evidence, and more specifically conveying some sense about what 'European education' could and/or should be, now as well as in the future (Lawn and Grek 2012). In that sense, these websites equally actively contribute to the Europeanization of education: by putting European countries side by side, for instance, some sense of 'Europe' as well as a sense of 'European education' are at once presupposed and actively being enacted (as is similarly regularly done with singular countries - ibid.; Piattoeva 2015). 
Furthermore, DG EAC is not only increasingly making use of websites itself, but is recently equally heavily propagating the incorporation of digital elements into daily educational practices. Partly to be situated within Europe's attempt to govern education throughout the lifespan (Green 2002), DG EAC is increasingly advocating for a more profound use of websites in (regular and lifelong) education in order to make learning possible everywhere, at any time and for anyone. In the larger context of the ET 2020 goals, Europe has recently pushed the Open Education (OE) agenda very promptly into the picture (European Union 2014; Muñoz et al. 2014). In this regard, the DG EAC's Open Education Europa platform ${ }^{3}$ serves as a dashboard where both qualitative and numerical evidence are portrayed, where good practices as well as statistics, benchmarks and other numerical indicators are distributed, and where visitors can collaboratively share and produce personal initiatives, opinions, and design principles on a dedicated section of the website. A broader rationale for the recent policy push toward a more digital (and hence, it is argued, a more open) education is, first, an ambition to catch up with other global regions that embraced the OE agenda way ahead of Europe as well as, second, an attempt to facilitate both the access to and the use of open educational resources (teaching material), examples (good practices) and courses as a whole (e.g. Massive Open Online Courses or MOOCs) (European Union2014). Hence, the Open Education Europa platform presents both hard and soft evidence regarding $\mathrm{OE}$ and popularizes the uptake of digital tools in education by displaying concrete $\mathrm{OE}$ practices.

In sum, and to conclude this preamble, this article aims to broaden our understanding of the role of websites and their concrete presentations in governing education in Europe. Inspired by areas known as software studies (Berry 2011 Fuller 2008) and the more well-known policy instrumentation approach (Lascoumes and Le Gales 2007), the paper advances that, and analyses how, websites are no neutral tools that just assist in passing along information, but that these digital instrumentalia are active devices themselves (e.g. Gobby 2015; Williamson 2015a). Its structure is as follows. In a first section, we briefly introduce the research approach that informed this article, viz. a relational approach that is broadly situated in the field of sociomaterial approaches to education (policy) (Fenwick and Edwards 2011). In particular, we center this approach around the notion of the diagram as a means in order to disentangle the relationship between the textual and the visible in contemporary digital assemblages. In the empirical part of the article, we analyze two websites of the DG EAC as case study: first, the website which reports of the ET monitor as an illustration of the uptake of digital tools in distributing and popularizing particular policy results and measures; second, the Open Education Europa website as an instance of the recent policy push toward a more systematically developed digital education. The article concludes with some reflections on the role of diagrams in Europeanizing the educational policy space and with the prospects of conducting diagrammatic analyses.

\section{Diagrammatic analysis}

Websites differ from traditional plain texts. This is obvious for a lot of different reasons, such as differences between scrolling through a digital text and turning paper pages; between hypertext and text; between interactivity and receptivity; etc. (Adami and Kress 2014). Many of these distinctions stem from the specific constitution of websites, which are composed out of more than text alone (equally incorporating pictures, movies, and so on). This characteristic of websites is often conceptualized in terms of their multimodality, that is to say: the way in which textual and visual elements are combined into one singular frame of screen real estate, and in which an interactive component of some sort (if only in the form of 'clicking') is present (Knox and Bayne2013; Lemke 2002).

It is this multimodal combination of texts and visuals into a single plane that we designate as a diagram (such as a map with a legend, an illustrated child book, a figure with a caption, etc.). Especially with respect to websites, diagrams abound. More often than not, textual elements are supplemented 
with visualizations of some sort: presentations of how various educational systems compare to each other in a graph; the recent upsurge of 'infoviz' renderings of a particular state of affairs in education policy; interactive interfaces that invite the visitor to perform actions that bring visual and textual matters together; etc. (Posner 2015). Drawing on a sociomaterial point of view, we specifically situate the agency of diagrams in the relations that are established between 'the textual' and 'the visual'. Just as a standalone text or figure is never a neutral carrier of information (Latour 1986, 1987), this combination of visual and textual elements on a screen is equally not neutral but performs different operations in and on itself. Or to say this otherwise: the manner in which textualities and visualities are combined on a screen works in a particular way.

In stressing the agency (i.e. the operations at work) that proliferates when relating the textual to the visual in a diagram, a sociomaterial approach does not conceive of diagrams as being representative renderings of an underlying reality, but rather as relational compositions whose operations can be analyzed on their own terms (Decuypere and Simons 2016a, 2016b; Savage 2009). As Drucker (2013) argues, the agency of diagrams is to be situated in 'A sustained engagement in knowledge production by dynamic figures that operate relationally rather than representationally. The elements of a diagrammatic system create value in relation to each other, not as an image of or stand-in for something else.' Hence, a key feature of diagrammatic analysis consists of scrutinizing the precise way in which this relational interplay between the textual and the visual domain is established. Often, this interplay is conceived in terms of non-conformity. Deleuze (1986) and Foucault (1983), for instance, both argued that even though these domains belong to a different order, it is precisely in the diagram that both realms find a place in which they meet without ever merging. The diagram, they state, constitutes a fabricated place in which one sees what one is talking about, and conversely, in which one talks about what one sees. According to Deleuze and Foucault, this is precisely the reason that diagrams exert so much power: in bringing together two orders that can never overlap, they constitute a technique, or even better, a device, that brings the visual and the articulable together in such a way that it 'never functions in order to represent a persisting world but produces a new kind of reality' (Deleuze 1986). Diagrams, hence, are active tools that do not faithfully represent an outside world; rather, they enact new spaces into being, call for specific ways of understanding oneself, the world, and for taking action upon that world (ibid.; Gitelman and Jackson 2013).

Even though all this might sound highly abstract, the power of diagrams is easily made tangible when considering the rhetorical and esthetic force that is inaugurated when combining visual with textual materials. This is highly pertinent with respect to education policy in general and European education governance in particular, where - we argue - rhetorical and esthetic persuasion are deployed as very effective governing techniques (Doyle 2015). Many research has convincingly demonstrated how data collection and analysis actively shapes the educational space to be envisaged, shaped, and steered, and how consequently different governable policy areas and subjects come into being (e.g. Lawn 2013; Piattoeva 2015). However, data collection and production do not constitute the ultimate steps in the coming into being of 'evidence': data equally have to be presented in a certain manner, and it is this manner that partly codetermines which policy spaces are enacted. If data constitute a governing device (Ozga 2009), then it makes very much sense to presume that the way in which these data are presented is equally a very determinative factor in how evidence starts to work and operate, and hence, the way in which websites (in)form the nature of education governance (Kitchin 2015). The concept of the diagram, and consequently, of diagrammatic analysis, is beneficial here in the double sense that: (1) it draws our attention to the specific ways in which policy spaces are being created over and above the numbers, good practices, etc., undergirding these spaces and (2) it recognizes the powerful ways in which educational policy knowledge and consequential desired ways of conduct and action are produced by highly authoritative devices (Drucker 2011). 
In the next sections, and as stated, we present a diagrammatic analysis of two websites as case studies. Rather than analyzing the entire relational assemblage of a website (see Decuypere, Ceulemans, and Simons 2014; Gorur 2013), we will specifically focus on the agency of some diagrams that can be found on these websites. As a selection of what can be found on these websites, this analysis does not aim to be all-encompassing, but rather explores the various ways in which text and visuals are combined, in order to obtain some sense of how evidence is portrayed nowadays (and not only the content of this evidence), what is being made present precisely (and what absent), and how such portrayal and presence consequently enacts particular spaces of action.

\section{The Education and Training monitor}

The Education and Training (henceforth ET) Monitor was launched in 2012 and comprises an annual analysis of the performance of the educational systems of Europe's member states. The ET Monitor is developed by the DG EAC, and can be conceived as a tool by means of which both Europe and its member states can analyze how well they perform on certain targets. Even though in theory (and legally) education is a responsibility of the member states and not of Europe (the principle of subsidiarity), the Monitor is nevertheless highly influential in how national policies frame and structure their priorities (Nóvoa 2013). According to the European Commission (EC), the Monitor is:

[A] new analytical tool that provides (...) empirical evidence (...). It is a succinct yet comprehensive overview of the core indicators regarding education and training systems in Europe, enabling the reader to compare and contrast recent progress as well as to identify the immediate challenges for Member States (EC 2012)

The Monitor more especially scrutinizes performance of the member states in view of objectives as determined by the Europe 2020 strategy. The 2020 strategy identified four general EU objectives that should tackle 'challenges in education and training systems' and that are phrased as follows (EC 2016):

- Making lifelong learning and mobility a reality;

- Improving the quality and efficiency of education and training;

- Promoting equity, social cohesion, and active citizenship;

- Enhancing creativity and innovation, including entrepreneurship, at all levels of education and training

In order to advance on these objectives, several targets and benchmarks ( 8 in total) have been set. These include: a diminishing of the amount of early school leavers to under $10 \%$; an employment rate of recent graduates of at least $82 \%$; etc. The prime function of the ET Monitor is to track the performance of Europe and its member states in progressing toward reaching these targets.

Moving from such general statements to how this Monitor is concretely being presented on the DG EAC's website then, the website first of all displays a large diagram that serves as the 2015 Monitor's logo (Diagram 1).

Diagram 1. The ET 2015 logo. 


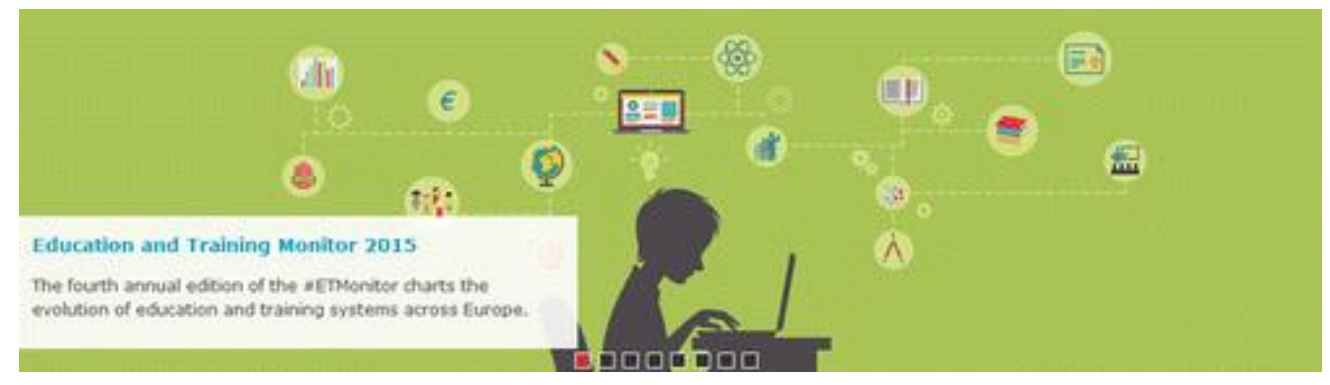

This diagram presents a highly specific view of 'education and training systems across Europe': the view this logo conveys, is one of education and training as being a highly individualized (safe for one 'classroom bulb' on the right and a 'classmates bulb' on the left) and even mechanic (all the sprockets) process in which a child gets acquainted with a lot of subjects through a computer. By placing another laptop floating above the child's head, the message that education is primarily (to be) effectuated through a computer is further invigorated. Moreover, this floating computer is the only object that is not encapsulated by a bulb. This stresses that the computer itself is not an object of learning, but rather a tool, or a vehicle, by means of which one can come to learn something. At the same time, the logo conveys the message that learning is a decontextualized phenomenon that can be taking place anywhere and anytime as long as one has a computer, a desk, and a chair - thereby heavily resonating with the DG EAC's focus on Open Education (which is, to be clear, not a subject of inquiry of the Monitor). Each part of a website, if only in the form of a stand-alone diagram such as the one above, in other words designates the end result of many choices that have been made with respect to what to present and how to present it precisely, but equally that each diagram is a produced accomplishment (rather than a neutral, representational, picture).

The concrete results of the Monitor are divided in five consultable formats. Two of these formats present country performances, either in the form of a one page summary or in the form of a detailed and more elaborate report. In order to scrutinize the diagrammatic operations that are at work in such documents - country reports are formatted into stable and unadaptable pdf documents that, in a certain sense, draw the visitor out of the website space - let us first take a look at how country performances of the member states were presented in the first edition of the ET Monitor (based on data gathered between 2007 and 2011, and issued in 2012) (Diagram 2).

Diagram 2. Table presenting a country's performance. 


\section{Belgium}

1. Performance summary

1.1 Overview of benchmarks and skill levels
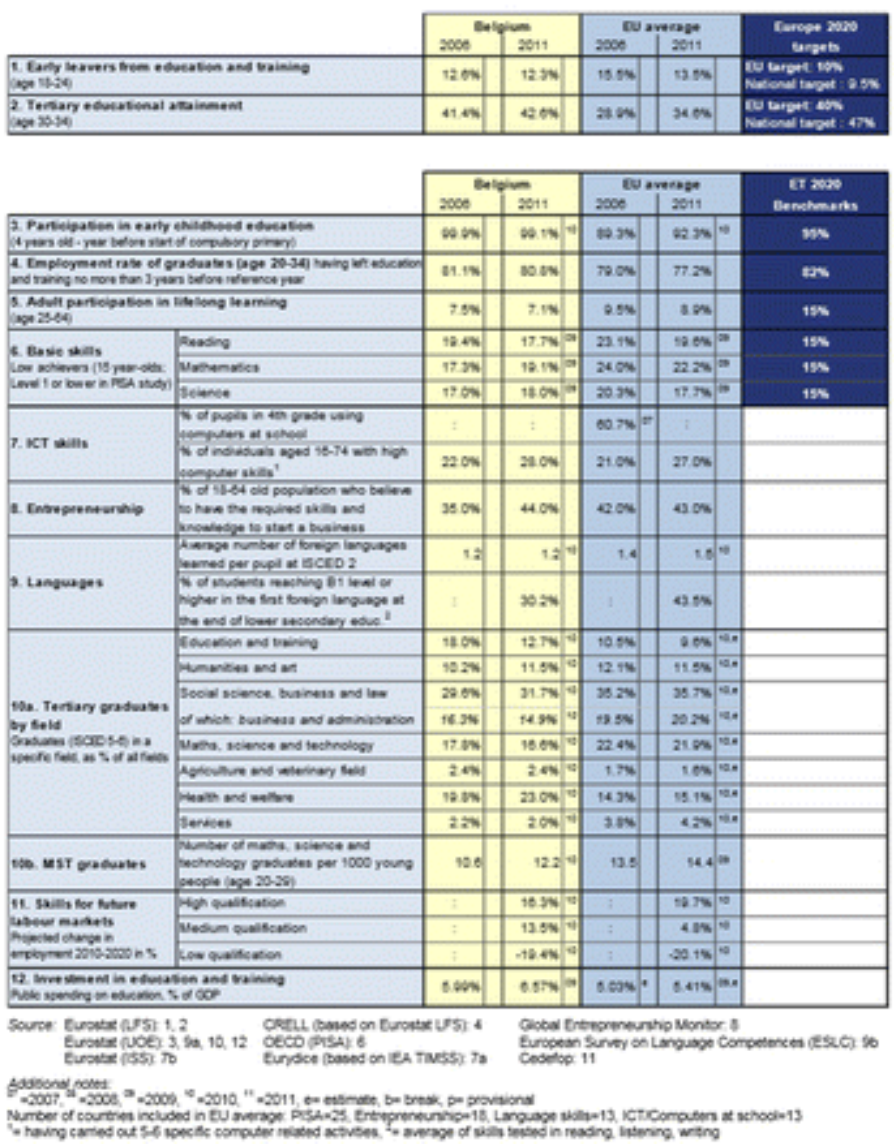

Each country report contains a version of this table - only the numbers differ. And for each country report, this table is positioned at the start of the document. As this diagram, which is a snapshot of the entire first page of Belgium's report, shows, there is no introduction at the beginning. Or conversely: the table could be considered as being the introduction of the report. By means of this standalone positioning at the very beginning of the document, this table obtains a highly authoritative status: the numbers are assumed to speak, quite literally, for themselves (i.e. they are not in need of any contextualizing or accompanying interpretation). Furthermore, positioning a table likewise, that is, with no additional (contextualizing) information, except for a mentioning of nine databases on which this table has been constructed at the bottom, presents the educational system of a whole country as being enumerable and calculable into 12 different domains. Even though a large number of descriptive statistics are being presented here, this table already constitutes an enormous crystallization and combination of a plethora of data (nine databases) into one single page. This double process of crystallization and combination is continued and made even more concentrated in the section that follows this table (Diagram $\underline{3}$ ).

Diagram 3. A country's performance in relation to ET 2020 targets and benchmarks. 
1.2 Position in relation to Europe 2020 targets and ET2020 benchmarks

Deviation (\%) from EU average and relative position to the EU benchmarks, top performers and low performers in EU27

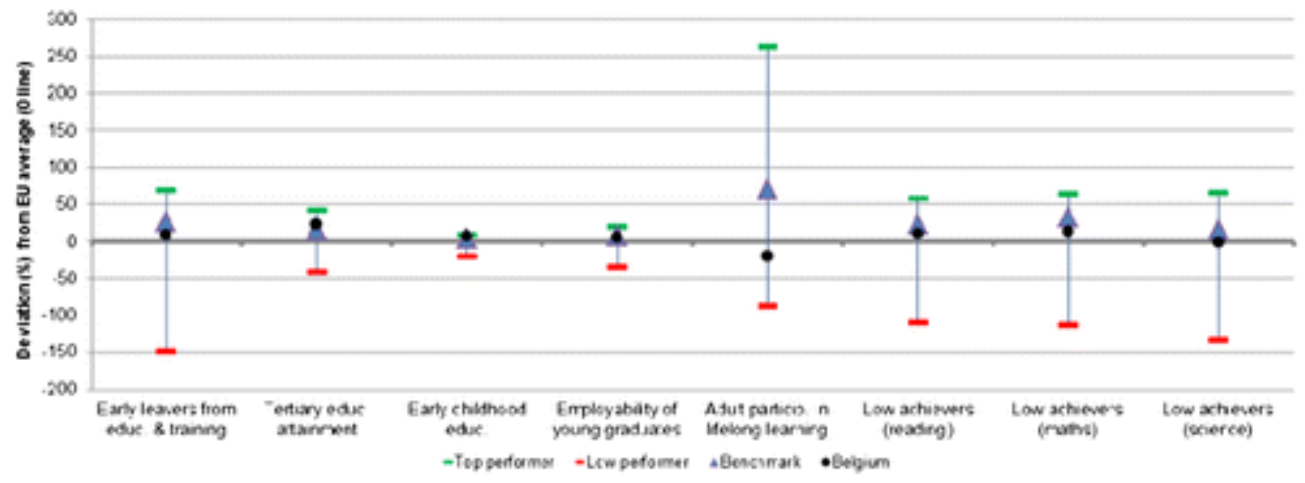

Again, this diagram is presented in a standalone manner - except for one sentence on top of the figure that gives a small amount of information regarding what is being displayed precisely in this graph. Hence, again a comparison of Belgium's performance with the ET 2020 targets and benchmarks is presented here, but this time the performances are even further reduced and crystallized: we only get to see the top of the table in Diagram $\underline{2}$ being visualized (even though the diagram at the same time displays more, by introducing calculated deviations). This diagram is expertly crafted, and presents specialized subject matter that is not so easily interpreted. What can we make of seeing and reading that Belgium's performance on tertiary educational attainment is about 25 percent deviating from the EU average (and we are making a rough estimation here, since the precise values corresponding to different units positioned on the graph are impossible to determine), for instance? Is 25 percent high or low? It 'sounds' quite high, but on the other hand, this makes Belgium still very closely positioned to the diagram's ' 0 line.' What does it mean that Belgium (as a dot) 'sits' on the top of the triangle (denoting a benchmark)? Of course, consultors of this report can make some sense about the precise meaning hereof, but in order to interpret this visualization rightfully, one has to possess a steady statistic background. The central message of this diagram for statistical laypeople seems to be that overall Belgium's performances are more or less in line with the average, but that its performance on one particular target, participation in lifelong learning, is subpar (under the benchmark, under the average, and way out of reach of Europe's best performer). Furthermore, by presenting each target as a subvisualization (in the form of a boxplot clearly demarcated from other parts of the diagram), an additional message conveyed through this diagram is that these targets are firmly separated from each other - and hence, that the performance of an educational system is rigidly separable into distinct categories (there is no singular number that encapsulates a member state's performance as a whole).

All this sound highly familiar, and perhaps for many readers these descriptions might appear as quite self-evident. That is, of course, precisely the point: tables and charts as the ones above have become so mundane that they almost seem natural. Their purpose is to represent the performance of an educational system as it really is, thereby adopting many representational techniques such as for instance a box plot or a table. As self-evident as they might look, different diagrams perform different operations, however, and this is rendered very clear when looking at how countries' performances are visualized and textualized in the 2015 edition of the ET Monitor (Diagram 4).

Diagram 4. A country's performances (2015 ET monitor). 


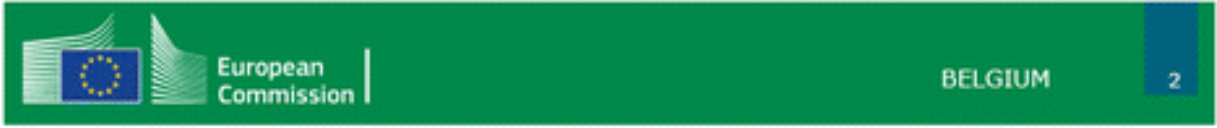

1. Key Indicators and Benchmarks

\begin{tabular}{|c|c|c|c|c|c|}
\hline & & & & & rage \\
\hline & & 2011 & 2014 & 2011 & 2014 \\
\hline fucational poverty and & d spending cutsi challenges for the eds & tien sec & & & \\
\hline & Reading & $\mathrm{t}$ & $16.196^{n}$ & $t$ & $17.896^{4}$ \\
\hline $\begin{array}{l}\text { Share of } 15 \text { year-olds with } \\
\text { underachievement in: }\end{array}$ & Maths & , & $19.0 \mathrm{~s}=$ & : & $22.1 \% \mathrm{a}$ \\
\hline & Science & $t$ & 17.746 & t & $16.6 \% 6^{\mathrm{L}}$ \\
\hline & $\begin{array}{l}\text { Public expenditure on education } \\
\text { as a percentage of GOP }\end{array}$ & $6.3 \%$ & $6.4 \times 6$ & 5.196 & 5.006 \\
\hline Education investment & $\begin{array}{l}\text { Public expenditure on education } \\
\text { as a share of total public expenditure }\end{array}$ & 11.746 & $11.8 \times 6^{n}$ & $10.5 \% 6$ & 10.396 \\
\hline Education attainment les & vels of young people across Europe & & & & \\
\hline Early leavers from & Man & 14.966 & $11.0 \%$ & $15.2 \%$ & 12.746 \\
\hline education and training & Women & $9.7 \%$ & $7.7 \%$ & $11.5 \%$ & 9.596 \\
\hline & Total & $12.3 \%$ & $9.0 \%$ & $13.4 \%$ & $21.1 \%$ \\
\hline Tertiary education & Man & $37.1 \%$ & $37.4 \%$ & 31.046 & $33.6 \%$ \\
\hline attainment & Women & $48.1 \%$ & $50.2 \mathrm{w}^{*}$ & 20.746 & $42.3 \%$ \\
\hline$(a g e-30-34)$ & Total & $42.6 \%$ & $43.8 \% *$ & $34.8 \%$ & 37.946 \\
\hline Dolicy levers for inclusiv & veness, quality and relevance & & & & \\
\hline $\begin{array}{l}\text { Early childhood education a } \\
\text { (parteipation from age } 4 \text { to }\end{array}$ & $\begin{array}{l}\text { and care } \\
\text { o starting age of compulsory education) }\end{array}$ & 90.146 & $98.1 \% \mathrm{~B}$ & $93.2 \%$ & $93.9 \% 6^{13}$ \\
\hline & Any topic (total) & 8 & $88.2 \% \mathrm{san}$ & 8 & $84.6 \mathrm{~N} \mathrm{w}^{\mathrm{a}}$ \\
\hline Teachers' participation in & Special needs education & , & $23.1 \% \mathrm{en}$ & 1 & $32.4 \% 6^{12}$ \\
\hline training & Multicultural settings & : & $0.3 * \mathrm{kn}$ & , & $13.2 \% \mathrm{a}$ \\
\hline & ICT skills for teaching & \llcorner & $37.24 \mathrm{sen}$ & 1 & 51.09612 \\
\hline Foreign language learning & $\begin{array}{l}\text { Share of ISCED } 2 \text { students learning } \\
\text { two or more foreign languages }\end{array}$ & $26.4 \%$ & $26.3 \% \mathrm{at}$ & 63.046 & $t^{4}$ \\
\hline $\begin{array}{l}\text { Share of ISCED } 3 \text { students } \\
\text { (VET) }\end{array}$ & in vocational education and training & 72.646 & $60.2 \mathrm{~s}^{\mathrm{an}}$ & 50.446 & $48.926^{\square}$ \\
\hline $\begin{array}{l}\text { Employment rate of } \\
\text { recent graduates by }\end{array}$ & ISCEO $3 \cdot 4$ & $73.5 \%$ & $67.4 \%$ & $71.3 * 6$ & $70.8 \%$ \\
\hline $\begin{array}{l}\text { education attainment } \\
\text { (age 20-34 having left }\end{array}$ & tsete s-8 & 86.046 & 86.246 & $82.5 \%$ & $20.5 \%$ \\
\hline $\begin{array}{l}\text { education } 1.3 \text { years } \\
\text { before reference year) }\end{array}$ & tsceo 3-A (total) & 00.896 & $79.0 \%$ & $77.1 \%$ & $76.1 \%$ \\
\hline & Inbound graduates mobility (bacheloe) & 8 & $6.4 \%=$ & ' & $: a$ \\
\hline Learning enotility & Inbound graduates mobility (master) & 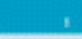 & $16.1 \%^{B}$ & 1 & 10 \\
\hline $\begin{array}{l}\text { Adult participation in } \\
\text { Ifelong learning } \\
\text { (age 25-64) }\end{array}$ & tsceo 0.e (total) & $7.1 \%$ & 7.146 & $8.9 \%$ & 10.746 \\
\hline
\end{tabular}

In Diagram $\underline{4}$, we are presented with a table that has a much more modern look, but that equally has some more substantive differences. First, member states are no longer presented as a stand-alone entity. Whereas in Diagram $\underline{2}$ the country 'Belgium' was visualized as a heading, now it is incorporated into a bar that equally contains the logo of the European Commission. This might seem trivial at first sight, but this is a move with quite some significance: from being displayed as a separate and demarcated entity (visualized as a heading - Diagram 2), Members states are now visually incorporated into one of Europe's central organizations, and hence, more portrayed as a part of Europe (rather than being a singular country on which Europe has performed an analysis). The benchmarks, second, have disappeared from the table, or more precise: their numerical valuehas disappeared. All we are presented now, are tiny blue dots indicating that a certain indicator is equally a benchmark. Third, these benchmarks are no longer grouped together on top of the table, but spread over the whole of the table in a quasi-randomly manner. This makes that these benchmarks catch the eye far less than was the case in the 2011 table. What stands out more visually than these benchmarks, is the blue column, which is clearly stressing the performance differences between 2011 and 2014. The focus of this table is, in other words, more directed toward how the Member State's performance has evolved since 2011, than toward a direct comparison with the European benchmarks themselves (and thus equally keeping member states distinct both from each other and from 'Europe' as a whole). More significantly, furthermore, is the observation that the numerical value of these benchmarks has dropped in favor of the benchmark (as a verbal concept) itself. This is even more clear when considering the 2015 visualization of countries' performances (see Diagram $\underline{5}$ ). 
Diagram 5. A country's performance in relation to other performers, ET 2020 targets and benchmarks (2015 ET monitor).

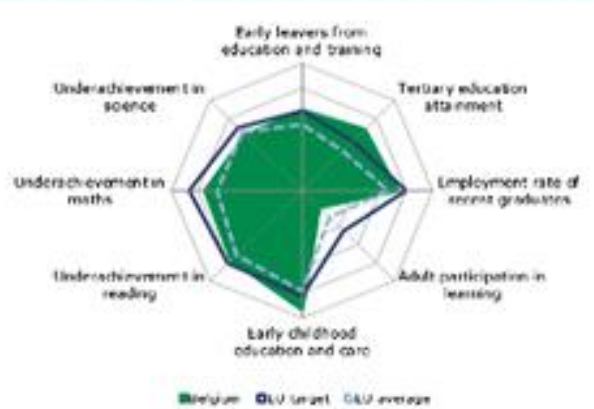

The difference between Diagrams $\underline{3}$ and $\underline{5}$ could hardly be more striking. Even though they claim to present similar information (the position of a member state in relation to other performers which are aggregated into a dotted line, targets, and benchmarks), and in a certain sense of course do present similar information, the message they convey is of a totally different nature. That is to say, the operations performed by the 2015 diagram are largely differing from the operations of the 2011 one. To start with, member states are no longer positioned to numbers, as was partly the case in the 2011 diagram. Rather, the viewer is presented a non-quantitative scale here, in the sense that what matters is not so much reaching a particular percentage, but rather being positioned in a favorable manner to two (dotted and full) lines and their correspondingwords. What is presented here is, in other words, a governing by pictures, in which the diagram(rather than 'numbers') starts to speak for itself. In the confines of one esthetic diagram, through highly specific operations a table is translated into a figure that sets out the points of action that a particular member state (which is now diagrammatically incorporated as a European member state) should undertake. Way more than the table, this translation of the table into an esthetic diagram without any numbers, has a massive rhetorical capacity: it opens up a space of action in view of eight visualized targets that one needs to act upon if one is positioned below two lines. This diagram literally enacts a policy space of optimization, a space that - through its esthetic rhetoric - shapes how member states should proceed, or rather, at which points they should pay explicit attention in order to improve the performances of their educational systems. By opening up a space of action likewise and hence by letting the hexagon and its corresponding words (rather than numbers) speak for themselves, unavoidably many aspects are literally out of the picture: by presenting relations between member states, EU targets and averages likewise, several things are equally rendered absent. It could, for instance, be argued that this hexagon addresses the first two EU objectives (lifelong learning and improvement of the quality of education and training), but that the other two objectives are completely absent from this inaugurated space of action: where are creativity and innovation to be found? What about social cohesion, active citizenship, and even entrepreneurship? In a certain sense, this resonates with the Monitor's logo (Diagram 1), where these elements are equally barely presented. This related interplay of presence and absence in diagrams as the ones discussed above, leads to a shifting focus as compared to the four general objectives set by the EU: in contrast to the four propagated aims, the concrete space of action that is opened by these diagrams is directed at the improvement of the measured and then visualized benchmarks - and hence less on 'softer' goals that are perhaps harder to measure, such as creativity and citizenship. 4

The diagrammatic instauration of the desired policy directions different member states ought to steer to, is even rendered more dramatically in the one-page summary of each country. Whereas the diagrams hitherto presented do still have the appearance of being mere objective representations of 
a country's performance, these one-page summaries always consist of two diagrams: first, a shortened version of the table presented in Diagram $\underline{4}$, and second, diagrams that explicitly point the finger at particular aspects of a country's educational performances that are in need of improvement or that are precisely a hallmark of excellent performance. These diagrams are at once highly normative (the point of attention is different for each country) and highly steering, with usage of directive parlance as 'need for more VET participation' or precisely affirmative vocabulary as 'Denmark: Lifelong learning is a reality for many (Diagram $\underline{6}$ ).'

Diagram 6. One page country reports.
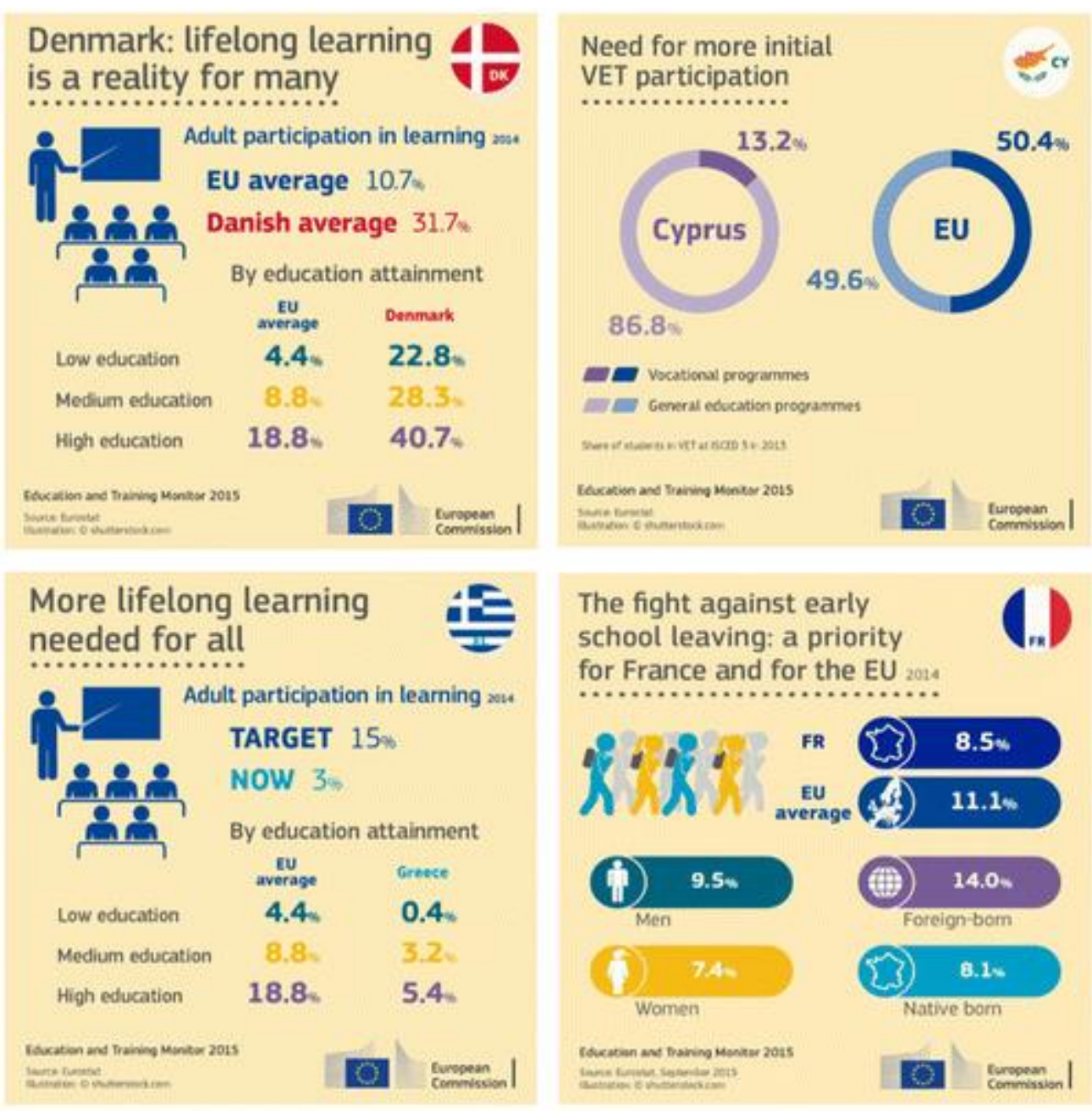

The persuasive and often explicitly admonishing operations presented in these diagrams steer the desired action even more directly than was the case in Diagram $\underline{5}$, by deploying a valuating vocabulary within the diagram itself and thereby prioritizing particular actions to be undertaken by each member state. Again, numbers do not speak for themselves in these diagrammatic spaces: they are supplanted with vocabularies and figures, which together present the end result of an ever more concentrated cascade of operations (from tests to data, from data to databases, from databases to singular numbers, from singular numbers to visualizations, from visualizations to diagrams) and make it legible.

The diagrams discussed up till now are all directed at the dissemination of data to interested visitors

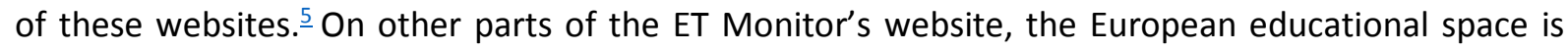
equally being shaped by a production of data by the visitors themselves. Some aspects of the Monitor have been translated into a series of interactive maps, on which the user can perform her own analyses (Diagram 7). 
Diagram 7. Interactive maps as data-producing diagrams.

\section{Education and Training Monitor: Interactive maps}

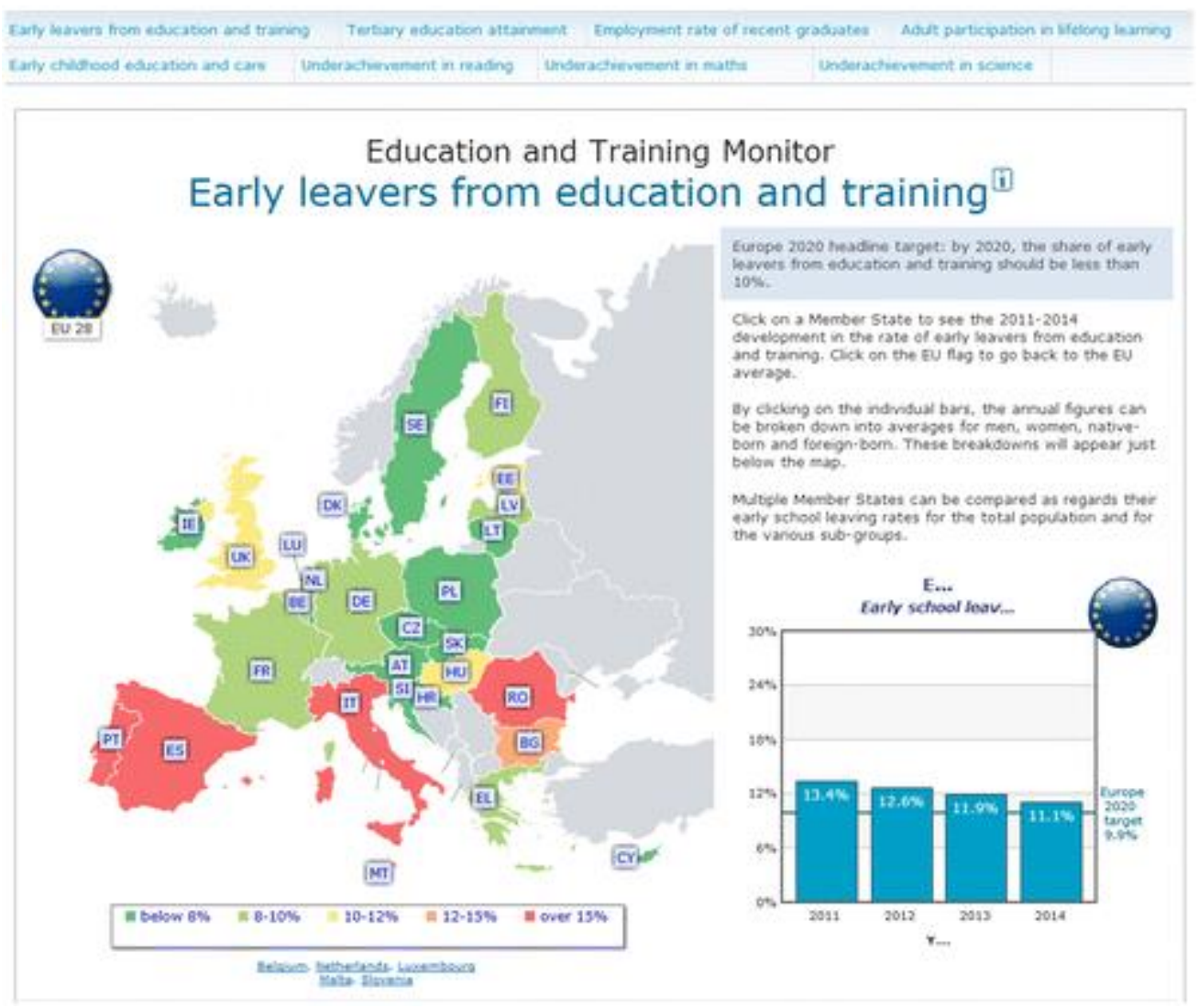

At the top of each diagram, and positioned very prominently as navigational entry points, we can again find the exclusive verbal formulation of each of the eight benchmarks (cf. Diagram $\underline{5}$ ). As their name suggests, these interactive maps all incite the user to have an active relation with the EU benchmarks. For each benchmark, a map of Europe is displayed that can be 'played with' (by clicking on a country or a bar), and that - through this interaction - results in additional performance data. Diagram $\underline{8}$, for instance, is a rendering of what the diagram shows when comparing 2014 data of two countries (and the annual evolution of the country last clicked upon, i.e. the UK).

Diagram 8. User-produced cross-country comparison. 


\section{Education and Training Monitor \\ Early leavers from education and training ${ }^{\text {(i) }}$}

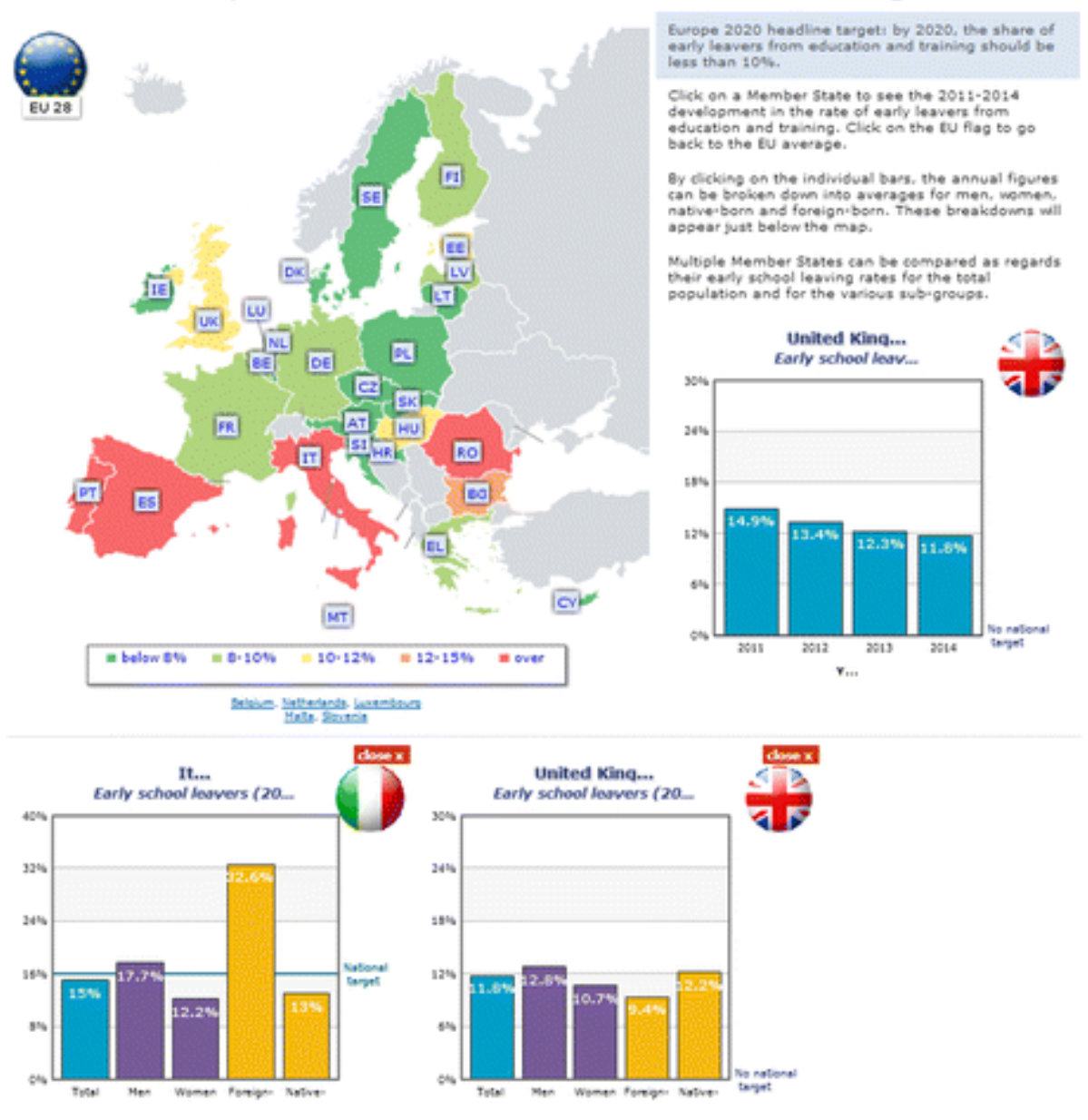

On this specific target, the diagram suggests that overall Europe seems to perform quite well: by means of a red-to-green color scale (which is not configurable by the user), the diagram suggests the user that most member states perform sufficiently - even though others are presented as being near to or even in a danger zone (orange-red). The comparison that is generated by clicking a yellow (UK) and a red (IT) member state, subdivides this benchmark into specific subpopulation performances (men or women, foreign or native). Other maps show more problematic performances on certain targets - or at least so seems this normative color scheme to suggest (e.g. most countries underperform in mathematical proficiency, consequently leading to a European map that is largely red and orange).

Again, such interactive diagrams render many things absent: they only refer to education and training as a country's performance on these benchmarks, thereby not only essentializing what education is or should be about, but equally reducing the comprehensiveness of the measures incorporated in the Monitor itself (cf. Diagram 4). The consequence hereof is that the type of analysis that can be effectuated in the confines of this interface is highly prefigured: the logic of comparison between countries is rendered diagrammatically here, but not each comparison is possible - such as for instance a comparison between regions of a member state (e.g. Flanders and Wallonia) or between other aspects than the benchmark performances themselves (e.g. expenditure on education; teachers' participation in training). Stated otherwise: even though such interactive tools contain an enormous amount of data that are crystallized and combined in one piece of screen real estate, such visualizations are at once extremely simplified versions of both the Monitor itself as well as of the broader spectrum of what education and training entail precisely. What such simplifications install, 
then, is a double process of (esthetic) seduction and (statistical as well as visual and verbal) abstraction, by means of which an are(n)a is opened in which countries are named (and where applicable shamed) by positioning them to each other.

In sum, the diagrammatized space fabricated by the Monitor is a space that not only operates through a governing by numbers and complex statistics. Rather than only obtaining authority through such matters, these diagrams equally govern by means of other forms of authority. Even though the Monitor is highly dependent on databases, numerical values, and output measures, the diagrams present on its website enact a form of authority that is equally dependent onattractivity (of the visuals incorporated), simplification (not only of reality into numbers, but equally of a highly selective portion of these numbers into visualizations), and words (sometimes accompanying numbers, but equally often substituting them).

\section{Open Education Europa}

As stated above, the advancement of digital ('open') education has only very recently been incorporated into the European education policy agenda. Due to a sense of unease with lagging behind other regions of the world, DC EAC is at present heavily betting on the potential of digital education in order to raise the adoption of digital devices into education as well as to address societal challenges such as the digital divide (or even more broadly, equity) (European Commission 2013). In order to showcase and offer access to already existing open educational resources (OER), the EC launched the Open Education Europa website that disseminates currently available OE practices and that equally provides the opportunity to expose one's own developed initiatives. Correspondingly, the portal consists of three general sections: a 'find' section where the visitor can search for open courses and OER; a 'share' section where users 'share and discuss solutions for a diverse range of educational issues' and an 'in-depth' section where scholarly research on the topic is being collected.

One of the most prominent features of the Open Education Europa website is the MOOCs scoreboard, which is referred to by a link on every page of the site. The scoreboard is designed as a snapshot of the amount of upcoming and past European MOOCs, and is presented in various ways: as downloadable database files, as (static) infographic, and lastly as interactive maps. The database files are spreadsheet documents, which list $\mathrm{OE}$ institutions, upcoming European MOOCs and MOOCs that have already been effectuated. The infographic and the interactive maps are translations of these spreadsheets into diagrams.

Diagram $\underline{9}$ presents a different Europe as the diagrams in the ET Monitor did. That is, even though the scoreboard uses almost exactly the same geographic portrayal of Europe (i.e. the same geographical base map), the countries that make up 'Europe' are different than the ones in the previous section. For instance, we can see that Russia, Norway, and Switzerland are included as part of Europe, whereas countries as Poland and Greece are not highlighted now. As to the reason why this is the case, this diagram does not give final clearance: the reason cannot be that Greece and Poland have not yet organized any MOOC for instance, since according to this diagram equally Russia did not deliver a MOOC yet (it does not have a balloon with numbers inscribed into its geographical territory). Furthermore, the color scheme used to colorize the different countries now consists of different shades of blue. Whereas the diagrams of the Monitor make use of a quantitative scale (the better a country performs, the greener it is colorized), this appears not to be the case here. Finland, for instance, conducted 6 MOOCs up till July 2015 and is yet colorized in a more intense blue than Portugal (15 MOOCs). What to make of these observations, and of this peculiar interplay of depicted presence and absence? What is the governed European education space precisely? Is it the one as displayed in Diagram $\underline{7}$, or rather that of Diagram $\underline{9}$ ? Where do its governable boundaries lie? These are suddenly 
puzzling questions, and these diagrams seem to suggest that its geographical borders shift according to the policy measurements at hand. Similarly, and in particular since we deal almost exclusively with numbers in this diagram, the choice of using a 'non-quantified blue scale' is equally rather puzzling especially since we are dealing with a scoreboard here, where the higher one's score is, the better one is assumed to perform. What do these colors convey precisely? The intense blue that is reserved for the UK and Spain seems to suggest that more intense colorization signifies a larger amount of MOOCs and certainly draws visual attention to them, but we cannot be entirely sure. In addition, by making the most recent numbers a lot larger than the already established MOOCs, this diagram prioritizes the present in the sense that currently conducted MOOCs are strongly emphasized over passed and upcoming ones.

Diagram 9. Infographic of the MOOCs scoreboard.

\section{The EUROPEAN MOOCS SCOREBOARD lastupdated 0.07.2015}

- Moocincur databue

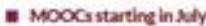

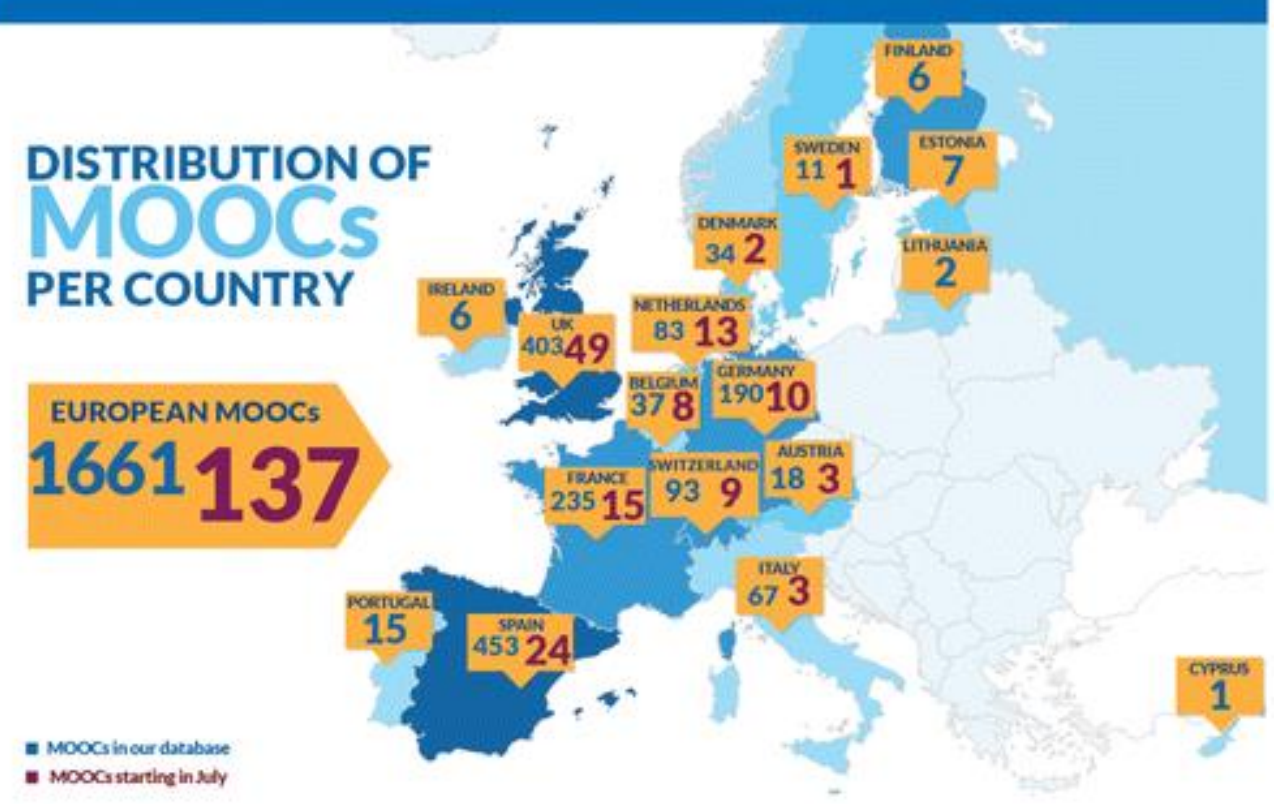

The situation gets even more complicated when taking a look at the interactive version of the scoreboard. Just like the Monitor's interactive maps, the interactive map of the scoreboard encourages an active relation between user and diagram. The interface allows for tweaking the MOOCs one wants to be visualized according to different subjects (e.g. applied sciences, business, humanities) and to different timeframes (present, past, future). In the following diagram, all subject matters are included, from a period spanning from the end of June 2015 to the end of February 2016 (Diagram 10).

Diagram 10. Interactive diagram of the MOOCs scoreboard. 


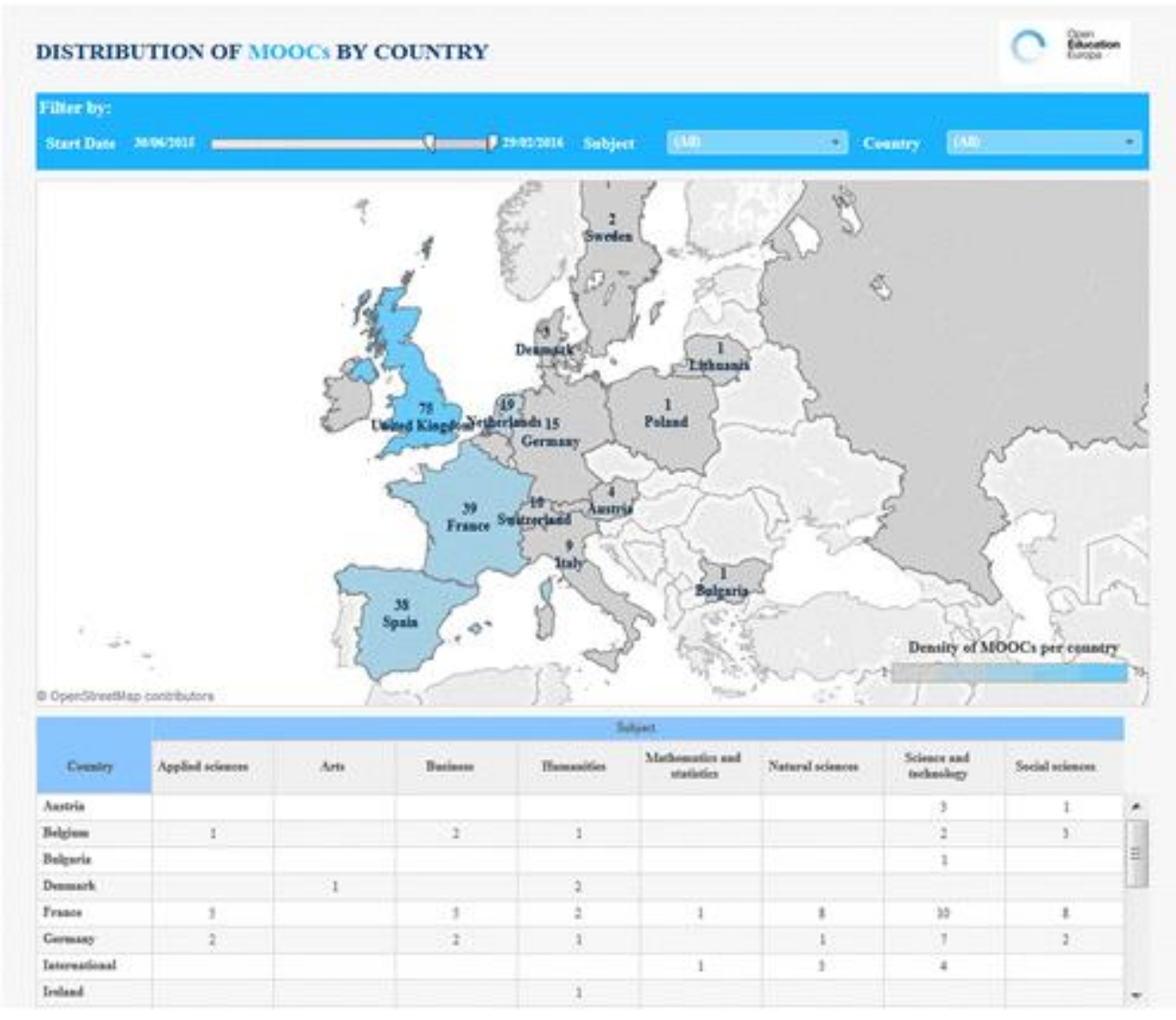

All of a sudden, countries as Poland and Bulgaria make their appearance, whereas other countries (e.g. Cyprus, Estonia, Norway) are rendered absent. The questions which space is precisely governed by Europe, which member states should take action, and what these diagrams present precisely, are apparently not easily answered. Next hereto, the scale on which member states are colorized, is now a gray-to-blue scale, and more significantly (again) quantitatively shaped. The message this diagram conveys is that only very few countries are worth to be colored blue - and hence, performing well thereby instoring a similar normative operation as the interactive visualizations of the Monitor.

The interactive mapping tool equally allows the user to analyze how MOOCs are distributed by subject (Diagram 11). The scale deployed in this regard is of yet another nature: it is alphabetical, where the closer the subject is to $A$ the lighter blue it is depicted, and the closer to $Z$ the darker the blue is. These subjects are, first, clearly demarcated from each other by placing them in circles. Second, the subject matters themselves have already been distinguished (not adaptable by the user) and seem sometimes overlapping (is 'business' not a 'social science'? What's the difference between 'applied sciences' and 'science and technology'?). Something similar applies for the countries enlisted below, where apparently sometimes countries seem to merge for reasons unknown (France vs. FranceGermany vs. Germany). Even though the user can tweak various parameters and play with these circles, the sort of analysis that is possible is, in other words, already highly preformatted and replete with choices that have been made in coding this diagram.

Diagram 11. Interactive diagram of the MOOCs scoreboard, focusing on subject matters. 


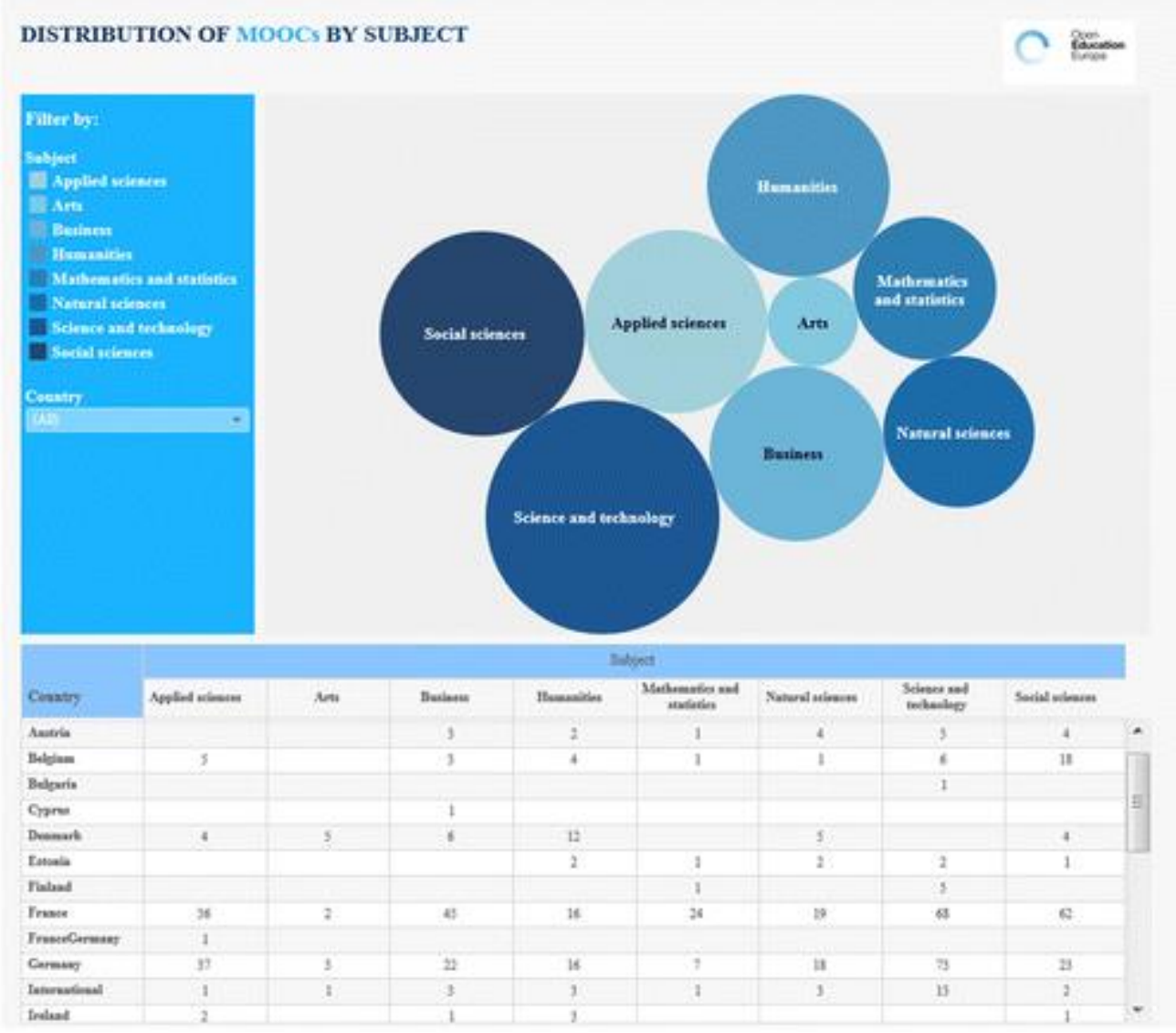

In sum, the diagrams present on the Open Education Europa website are largely characterized by the calculation and presentation of amounts (and thereby in the process making several parts of Europe present or absent). All the diagrams presented in this section operate according to an enumerative and augmentative logic, which suggests the user that the more courses in the more subject matters one provides, the better (regardless of any form of quality check whatsoever). Even though not explicitly addressed here, the same applies for the 'share'-section of the website, where seemingly endless lists of blogs, good practices, and so on are placed. The consequential space of action that is inaugurated here, is then not so much a view on action as optimization, but rather as increasementa logic that stipulates that the more one has (scored), the better one has performed. Correspondingly, these diagrams strongly resonate with the 'policy by numbers' approach, in which numbers are assumed to speak for themselves. In an enumerating and augmenting logic (rather than in a logic of amelioration and optimization), this indeed is the case: having a higher number as such is at once a legitimate and a promoted action (in order to 'have the most' or 'be the leader' - Open Education Europa 2015). As such, and perhaps because Europe's OE focus is still in its inception phase, this diagrammatized policy space is all about vast amounts of practices and about popularity: the more courses one provides as a member state, the more popular OE is rendered (and this without even having to take into account the amount of people who followed these courses). Equally, perhaps due to the novelty of this policy focus, benchmarks and targets have not (yet?) appeared in this policy space, and the focus of these websites is more on lists of initiatives (MOOCs, OER, good practices, inspirational examples, etc.) than on more explicitly steering targets and benchmarks. The logic at work is a logic stipulating that steering toward more, is prioritized above steering toward better, or stated otherwise: that more is better. 


\section{Discussion and conclusion}

The aim of this paper was to contribute to our understanding of the specific ways in which digital devices are contributing to European education governance. Whereas the role of data visualization in shaping education policy has of course already been subject of concrete analysis (e.g. Lawn 2013), much is yet to be known about how digital devices such as websites operate as an active policy instrument (Lascoumes and Le Gales 2007; Selwyn 2015). By invoking the concept of the diagram and through an analysis of the operations at work when the visual and the articulable are combined into one singular space, this paper has attempted to open up some of the elements of the 'black boxes' that these websites often are. That is to say, rather than conceiving of websites as neutral hatchways that merely transmit information and taking them at face value, the intention of this paper was to unfold how diagrams embedded in websites function and act precisely and how they assist in coconstructing policy spaces and consequential (popularized) spaces of action. Of course, this analysis has only presented a selection of diagrams that can be found on these websites. In that sense, this article did not aim to give a representative account of all operations performed in these digital spaces, but was rather centrally interested in the usage and roles of diagrams with respect to their contributing to the enactment of a specific kind of European educational space. This analysis generally shows that diagrams presented on websites enact 'Europe' as an entity that is constantly at once being in the making as well as made already: assemblages of textual and visual elements variously present Europe as a uniform geographical entity (a singular whole); as a (loosely coupled) collection of national member states; as a gathering of numbers or of concrete examples; and so on. By means of diagrams, websites enact varying sorts of Europe depending on the particular message one wants to propagate. Overall, and depending on these varying intentions, these diagrams explicitly present a Europe that is a becoming, yet at the same time equally a being-there already. As such, this analysis does not seek to denounce the 'historical journey' that European education policy has made until now; rather than that, it has shown that the present educational state of Europe is equally inherently linked to a desired future that needs to be acted upon now already (Nóvoa and Yariv-Mashal2003; Lawn and Grek 2012). By presenting collections of diagrams, the websites analyzed in this paper acquire the remarkable feat that they merge temporal and spatial features of what it is to be (in) Europe nowadays: they inaugurate a self-understanding in the visitors of these websites that is temporal (that is, at once positioned in the present and the future) through beingenvironmental (that is, by constituting a whole through diagrammatically responsibilizing its loosely coupled parts). In a certain way, then, it could be stated that diagrams as the ones introduced above constitute a pinnacle of Europeanizing education: by presenting a Europe that is at once fabricated and (hence) possible to remake, becoming real and real already, they establish and invigorate spaces of action pertaining to the educational field as both European andEuropeanizing actions. In what follows, and in drawing this article to a close, three additional more specific critical points of attention that emerge from this diagrammatic analysis are highlighted.

First, the diagrammatic analysis presented here has elucidated the operations at work when the visible and the articulable are combined on a singular webpage. Naturally, this combinatory capacity is not new on itself - as if this would only and uniquely pertain to digital media. However, but the specific composition of websites allows for a more profound intertwining of these elements than can be done in a traditional book, for instance. Diagrammatic analyses can contribute to the disentanglement of multimodal presentation and how this presentation starts towork in a particular way-something that is often conceived as mundane and procedural, but that has very significant and powerful consequences (Selwyn 2015). Diagrams are very potent tools: as a meeting place between the visible and the articulable, they have a massive rhetorical capacity which, we argued, opens up particular 
spaces of action imbued with values and norms, and which, in the same process, obfuscates many elements that are consequentially rendered absent. The power of these diagrams, in other words, is precisely that they manage to portray what they present as natural and self-evident ways of representation (such as for instance the performances of a country in a table, or a country as being a European member state) that make the actions to be undertaken as more or less unquestionable (such as ameliorating one's performance so that it is in line with dotted and full lines). Furthermore, diagrammatic analyses allow to specify and complement analyses that are more focally directed at the level of the non-digital technologies and modes of analysis deployed by education policy (Grek 2008; Olssen and Peters 2007). This paper has, for instance, shown that even though numbers are of pivotal importance in the construction of European spaces of governance, these numbers cannot act in and on themselves, but need to be related to by other actors. As sociomaterial approaches often state, 'governance' is not something that exists 'out there,' as a floating (yet flexible) macro-structure determining what other actors can do (Latour 2005). In a relational vein, actors (such as numbers) are only of importance if they are being related to by many other actors. To state this otherwise, in a sociomaterial approach actors do not possess some sort of natural power, but gain authority only in as far as other actors relate to these actors. In the websites analyzed here, numbers, for instance, are in need of visual and textual complementation and commensuration, and categorization and demarcation. Even when numbers are the only (policy) actors present, they only gain relevance (or better, authority) in relation to other numbers presented and inscribed in these diagrams. When numbers are related to other numbers, the logic that is made operable is a logic that desires unequivocal increasement. The presently emerging focus on digital education is a prototypical example in this respect, where more as such is better as such. In and through the presentation of the Monitor, however, numbers are most of the time related to a manifold of other actors: they are supplanted with benchmark-talk and visual steering (facilitated by digital technologies) toward very specific forms of optimization. Optimization is different from increasement in the sense that it not solely demands 'more' of something, but that this more has to abide to particular requirements and characteristics (as outlined by specific benchmarks). This has the double effect that, first, education is increasingly decontextualized and reduced to what can be measured, but second equally that even some of DC EAC's objectives themselves are being reduced and put into the background. This persuasive and rhetorical capacity is even further invigorated with the proliferation of digital techniques such as interactive maps with which the user can 'play': such diagrams even more dramatically install the illusion of complete visibility and intelligibility, thereby conveying a sense that they present 'all there is to know' or 'all that is relevant to know.' As non-human agents interacting with human of users of these websites, the lines of code inscribed into these diagrams are characterized by an immanent normativity, that is, they play a very significant role by co-constructing what can be analyzed, how it can be analyzed, what should be done, etc. In brief: the operations of digital technologies (the diagrams presented, the code which makes them come into being) co-construct specific enactments of what education is, how it should be approached, and how it should be acted upon (Berns 2009; Kitchin2015).

Related hereto, and second, diagrams tend to privilege ease of use and face value above critical engagement with the facts at hand. The diagrams on these websites largely have the aim to represent factual state of affairs, and accomplish this very convincingly. But what these diagrams tend to obfuscate are areas of uncertainty and conflicting opinions, issues of ethics, politics, and responsibility - even though we have argued that for instance ethical and normative issues are often implicitly inscribed in the diagrams' 'second text' (Fenwick 2015; Kitchin, Perkins, and Dodge 2009). Their propagated matter-of-factness hence not only leads to a privileging of what can be measured, it equally leads to a privileging of what one deems to be true - thereby omitting contest, conflicts, difference, etc. Even though interactive maps are in principle especially well-suited for presenting 
different points of view or different perspectives on the matters at hand, there is remarkably little attention to alternative points of view or contested states of affairs and how to present these in a visual manner. In a certain sense, this puts professional judgment on hold: why would one need a professional to interpret what is so obviously presented? These diagrams do not need professionals who are able to digest interpretations of what is presented; they need experts who know how to advance on particular parameters and depicted lacunas which are often admonishingly visualized (by colors and scales) and textualized in these diagrams themselves.

Yet, and this is our ultimate point, if diagrams are such a powerful way of presenting current states of affairs, perhaps the point can be raised that we are in need of alternative possibilities of presentations; of diagrammatic presentations that are equally persuasive and powerful but that are precisely tools of inquiry. There is a very compelling case to be made here that the lack of alternative ways of shaping digital diagrams is partly to be attributed to their seeming naturalness: diagrams as the ones discussed in this article seem to have become so self-evident that there is hardly any space left for reimagining how such diagrams could be deployed (Drucker2011; Posner 2015). Deploying diagrams as tools of inquiry, rather than as objective representation, would allow for displaying such uncertainties, ambivalences, and perhaps even allow a space of professional judgment to be inaugurated (Decuypere and Simons 2016b). This, however, presumes that we would get more acquainted with composing such tools ourselves, in brief: that we all get - somewhat, somehow - more digitally literate.

\section{Notes on contributor}

Mathias Decuypere is a postdoctoral researcher and teaching fellow at the University of Leuven. In his $\mathrm{PhD}$, conducted as research fellow of the Research Foundation Flanders, he investigated the role of digital technologies in current academic practices. In order to do so, he developed a sociomaterial and a sociotopological approach that focuses on the relations between different actors (rather than on these individual actors per se). His main research interests are the role of digitization and digital technologies on different educational sectors, open and higher education, the specificity of different educational practices, and the policy context in which these are embedded.

\section{Note}

All diagrams are retrieved from Europe's Education and Training website and the Open Education Europa website.

Diagrams of the ET section were retrieved from: http://ec.europa.eu/education/,http://csdle.lex.unict.it/Archive/LW/Data\%20reports\%20and\% 20studies/Reports\%20and\%20\%20communication\%20from\%20EU\%20Commission/20121128010808 SWD-377 2012 enpdf.pdf, http://ec.europa.eu/education/tools/docs/2015/monitor2015belgium en.pdf, http://ec.europa.eu/education/tools/docs/2015/monitor15-countrysheets en.pdf, http://ec.europa.eu/education/dashboard/index en.htm

Diagrams of the Open Education Europa section were retrieved from:http://openeducationeuropa.eu/es/open education scoreboard

\section{Disclosure statement}

No potential conflict of interest was reported by the author.

\section{Notes}


Decuypere, M. (2016). Diagrams of Europeanization. Journal of Education Policy, 31 (6): 851-872

\section{1. http://ec.europa.eu/education/tools/et-monitor en.htm}

2. http://ec.europa.eu/epale/

\section{3. http://www.openeducationeuropa.eu}

4. The absence of such notions not only pertains to these diagrams, but even to the Monitor's country reports as a whole, which never mention these dimensions.

5. NB: the databases on which these diagrams are based, are equally often available for additional analysis and can be retrieved from the original database developers such as the OECD or Eurostat.

\section{References}

1. Adami, Elisabetta, and Gunther Kress. 2014. "Introduction: Multimodality, Meaning Making, and the Issue of 'Text'." Text \& Talk 34 (3): 231-237. doi:10.1515/text-2014-0007.

2. Ball, Stephen J. 2015. "Education, Governance and the Tyranny of Numbers." Journal of Education Policy 30 (3): 299-301. doi:10.1080/02680939.2015.1013271.

3. Berns, T. 2009. Gouverner sans Gouverner: Une Archéologie Politique de La Statistique [Governing without Governing. A Political Archeology of Statistics]. Paris: Presses universitaires de France.10.3917/puf.berns.2009.01

4. Berry, David M. 2011. The Philosophy of Software: Code and Mediation in the Digital Age. Palgrave Macmillan.http://philpapers.org/rec/BERTPO-21.10.1057/9780230306479

5. Decuypere, Mathias, and Maarten Simons. 2016a. "What Screens Do: The Role(s) of the Screen in Academic Work." European Educational Research Journal 15 (1): 132-151. doi:10.1177/1474904115610335.

6. Decuypere, Mathias, and Maarten Simons. 2016b. "Relational Thinking in Education: Topology, Sociomaterial Studies, and Figures." Pedagogy, Culture \& Society 24 (): 371-386. doi:10.1080/14681366.2016.1166150.

7. Decuypere, Mathias, Carlijne Ceulemans, and Maarten Simons. 2014. "Schools in the Making: Mapping Digital Spaces of Evidence." Journal of Education Policy 29 (5): 617-639. doi:10.1080/02680939.2013.865081.

8. Deleuze, Gilles. 1986. Foucault. http://philpapers.org/rec/DELF-3.

9. Doyle, Sarah. 2015. "Data Vizualization as Socio-Digital Pracitce." In Coding/Learning, edited by BenWilliamson, 56-58. Stirling: University of Stirling.

10. Drucker, Johanna. 2011. "Humanities Approaches to Graphical Display." Digital Humanities Quarterly 005 (1).

11. Drucker, Johanna. 2013. "Diagrammatic Writing." New Formations: A Journal of Culture/Theory/Politics 78 (1):83101. https://muse.jhu.edu/journals/new formations/v078/78.drucker.html.[CrossRef]

12. Edwards, Richard. 2015. "Software and the Hidden Curriculum in Digital Education." Pedagogy, Culture \& Society 23 (2): 265-279. doi:10.1080/14681366.2014.977809. 
Decuypere, M. (2016). Diagrams of Europeanization. Journal of Education Policy, 31 (6): 851-872

13. European Commission. 2012. Education and Training Monitor 2012. http://eurlex.europa.eu/legal-content/EN/TXT/HTML/?uri=CELEX:52012SC0373\&from=pl

14. European Commission 2013. "Opening up Education: Innovative Teaching and Learning for All Trhough New Technologies and Open Educational Resources." http://eurlex.europa.eu/legal-content/EN/TXT/PDF/?uri=CELEX:52013DC0654\&from=EN.

15. European Commision. 2016. Strategic Framework - Education \& Training 2020. http://ec.europa.eu/education/policy/strategic-framework/index en.htm

16. European Union 2014. Opening up Education - Education Policy - EU Bookshop.http://bookshop.europa.eu/en/opening-up-educationpbNC0214816/?CatalogCategoryID=QN4KABsteOYAAAEjFZEY4e5L.

17. Fenwick, Tara. 2015. "Professional Responsibility in a Future of Data Analytics." In Coding/Learning, edited by Ben Williamson, 68-72. University of Stirling.

18. Fenwick, Tara, and Richard Edwards. 2011. "Considering Materiality in Educational Policy: Messy Objects and Multiple Reals." Educational Theory 61 (6): 709-726. doi:10.1111/j.17415446.2011.00429.x.

19. Fenwick, Tara, and Richard Edwards. 2016. "Exploring the Impact of Digital Technologies on Professional Responsibilities and Education." European Educational Research Journal 15 (1): 117-131.

20. Foucault, Michel. 1983. This is Not a Pipe. https://books.google.com/books?hl=n|\&|r=\&id=M9YwciWmBbMC\&pgis=1.

21. Fuller, Matthew. 2008. Software Studies: $A$ Lexicon. https://books.google.com/books?hl=nl\&lr=\&id=LFJ3ashVBulC\&pgis=1.10.7551/mitp ress/9780262062749.001.0001

22. Gitelman, Lisa, and Virginia Jackson. 2013. "Introduction: Raw Data is an Oxymoron." 114.https://books.google.com/books?hl=n|\&|r=\&id=oARaHF4D6h0C\&pgis=1.

23. Galloway, Alexander R. 2012. The Interface Effect. Cambridge: Polity Press.

24. Gobby, Brad. 2015. "Obliged to Calculate: My School, Markets, and Equipping Parents for Calculativeness." Journal of Education Policy 31 (4): 421-431. doi:10.1080/02680939.2015.1083124.

25. Gorur, Radhika. 2013. "My School, My Market." Discourse: Studies in the Cultural Politics of Education 34 (2):214-230. doi:10.1080/01596306.2013.770248.

26. Green, Andy. 2002. "The Many Faces of Lifelong Learning: Recent Education Policy Trends in Europe."Journal of Education Policy 17 (6): 611-626. doi:10.1080/0268093022000032274.

27. Grek, S. 2008. "From Symbols to Numbers: The Shifting Technologies of Education Governance in Europe." European Educational Research Journal 7 (2). Symposium Journals: 208-218.

28. Grek, Sotiria. 2010. "International Organisations and the Shared Construction of Policy 'Problems': Problematisation and Change in Education Governance in Europe." European Educational Research Journa/9 (3): 396-406. doi:10.2304/eerj.2010.9.3.396. 
Decuypere, M. (2016). Diagrams of Europeanization. Journal of Education Policy, 31 (6): 851-872

29. Hargreaves, David H. 2003. Education Epidemic: Transforming Secondary Schools through Innovation

Networks. https://books.google.com/books?hl=n|\&lr=\&id=XdnS6nGXQWcC\&pgis=1.

30. Kitchin, Rob. 2015. "Foreword: Education in Code/Space." In Coding/Learning, edited by Ben Williamson,1-3. Stirling: University of Stirling.

31. Kitchin, Rob, Chris Perkins, and Martin Dodge. 2009. "Thinking about Maps." Routledge.http://eprints.maynoothuniversity.ie/2875/1/RK Thinking about maps.p df.

32. Knox, Jeremy, and Siân Bayne. 2013. "Multimodal Profusion in the Literacies of the Massive Open Online Course." Research in Learning Technology 21 (1063519): 1-14.

doi:10.3402/rlt.v21.21422.

33. Lascoumes, Pierre, and Patrick Le Gales. 2007. "Introduction: Understanding Public Policy through Its Instruments? From the Nature of Instruments to the Sociology of Public Policy Instrumentation." Governance 20 (1): 1-21. doi:10.1111/j.1468-0491.2007.00342.x.

34. Latour, Bruno. 1986. "Visualization and Cognition: Thinking with Eyes and Hands." Knowledge \& Society 6:1-40. http://hci.ucsd.edu/10/readings/Latour(1986).pdf.

35. Latour, Bruno. 1987. Science in Action: How to Follow Scientists and Engineers through Society.https://books.google.com/books?hl=nl\&|r=\&id=sC4bk4DZXTQC\&pgis=1.

36. Latour, Bruno. 2005. Reassembling the Social: An Introduction to Actor-networktheory. Oxford: Oxford University Press.

37. Lawn, Martin. 2006. "Soft Governance and the Learning Spaces of Europe." Comparative European Politics4 (2/3). Palgrave Macmillan: 272-288. doi:10.1057/palgrave.cep.6110081.

38. Lawn, Martin. 2011. "Standardizing the European Education Policy Space." European Educational Research Journal 10 (2): 259-272. doi:10.2304/eerj.2011.10.2.259.

39. Lawn, Martin. 2013. The Rise of Data in Education Systems: Collection, Visualization and Use. Symposium Books. https://books.google.com/books?hl=nl\&|r=\&id=fCVwCQAAQBAJ\&pgis=1.

40. Lawn, Martin, and Sotiria Grek. 2012. Europeanizing Education: Governing a New Policy Space.https://books.google.com/books?hl=nl\&lr=\&id=lixwCQAAQBAJ\&pgis=1.

41. Lemke, J. L. 2002. "Travels in Hypermodality." Visual Communication 1 (3): 299-325. doi:10.1177/147035720200100303.

42. Muñoz, Jonatan Castaño, Christine Redecker, Riina Vuorikari, and Yves Punie. 2014. "Open Education 2030: Planning the Future of Adult Learning in Europe." Open Learning: The Journal of Open, Distance and E-Learning, March. Routledge. http://www.tandfonline.com/doi/abs/10.1080/02680513.2013.871199.

43. Nóvoa, António. 2013. "The Blindness of Europe: New Fabrications in the European Educational Space."Sisyphus - Journal of Education. http://revistas.rcaap.pt/sisyphus/article/view/2832.

44. Nóvoa, António, and Tali Yariv-Mashal. 2003. "Comparative Research in Education: A Mode of Governance or a Historical Journey?" Comparative Education 39 (4): 423-438. 
45. Nóvoa, António, Luís Miguel Carvalho, and Cristina Yanes. 2014. "La Comparaison Comme Politique: Le Tournant Du Début Du 21e Siècle [Comparison as Politics: The Turning Point of the Beginning of the 21st Century]." Revue Suisse Des Sciences de L'éducation 36 (2): 265282. http://rsse.elearninglab.org/wpcontent/uploads/2014/10/SZBW 14.2 Thema Novoa.pdf.

46. Olssen, Mark, and Michael A. Peters. 2007. "Neoliberalism, Higher Education and the Knowledge Economy: From the Free Market to Knowledge Capitalism." Journal of Education Policy 20 (3): 313-345. doi:10.1080/02680930500108718.

47. Open Education Europa 2015. "Almost 1,700 Courses Listed in the New European MOOCs Scoreboard." http://openeducationeuropa.eu/en/news/almost-1700-courses-listed-neweuropean-moocs-scoreboard.

48. Ozga, Jenny. 2009. "Governing Education through Data in England: From Regulation to SelfEvaluation." Journal of Education Policy 24 (2): 149-162. doi:10.1080/02680930902733121.

49. Piattoeva, Nelli. 2015. "Elastic Numbers: National Examinations Data as a Technology of Government."Journal of Education Policy 30 (3): 316-334. doi:10.1080/02680939.2014.937830.

50. Posner, Miriam. 2015. "The Radical Potential of the Digital Humanities: The Most Challenging Computing Problem is the Interrogation of Power." Keynote Delivered at the Keystone Digital Humanities Conference.http://blogs.Ise.ac.uk/impactofsocialsciences/2015/08/12/theradical-unrealized-potential-of-digital-humanities/.

51. Rose, Nikolas. 1999. Powers of Freedom: Reframing Political Thought. Cambridge University Press.

52. Savage, M. 2009. "Contemporary Sociology and the Challenge of Descriptive Assemblage." European Journal of Social Theory 12 (1): 155-174. doi:10.1177/1368431008099650.

53. Selwyn, Neil. 2015. "Data Entry: Towards the Critical Study of Digital Data and Education." Learning, Media and Technology 40 (1): 64-82. doi:10.1080/17439884.2014.921628.

54. Selwyn, Neil, Michael Henderson, and Shu-Hua Chao. 2015. "Exploring the Role of Digital Data in Contemporary Schools and Schooling-'200,000 Lines in an Excel Spreadsheet'." British Educational Research Journal 41 (5): 767-781. doi:10.1002/berj.3186.

55. Simons, Maarten. 2014. "Governing Education without Reform: The Power of the Example." Discourse: Studies in the Cultural Politics of Education 6306 (October): 1-20. doi:10.1080/01596306.2014.892660.

56. Williamson, Ben. 2015a. "Digital Education Governance: Data Visualization, Predictive Analytics, and 'Real-Time' Policy Instruments." Journal of Education Policy 1-19. doi:10.1080/02680939.2015.1035758.

57. Williamson, Ben. 2015b. "Governing Software: Networks, Databases and Algorithmic Power in the Digital Governance of Public Education." Learning, Media and Technology 40 (1): 83105. doi:10.1080/17439884.2014.924527. 